\title{
The Re-emergence of Core Region Growth: A Return to the Metropolis?
}

\author{
William H. Frey \\ Population Studies Center \\ The University of Michigan \\ Ann Arbor, MI 48109 USA
}

\section{INTRODUCTION}

When Vining and his collaborators first called our attention to the pervasiveness of core region decline in the world's industrialized nations (Vining and Kontuly 1978; Vining and Pallone 1982), it seemed appropriate to link this decline to a parallel phenomenon the counterurbanization process. At least in the United States, the 1970 s core region losses were disproportionately borne by the largest metropolitan areas in that region, and peripheral region gains were, to a greater extent than before, shared by those regions' smaller metropolitan areas and nonmetropolitan territory (Frey and Speare 1988). The link between regional and urbanization shifts was implicit in the Vining et al. definitions of core regions, which encompassed each nation's largest and, generally, most industrialized metropolitan areas. Moreover, this link was made explicit in Vining and Pallone's explanations for core-to-periphery redistribution, which emphasized the diseconomies of core region agglomerations and the increasing competitive advantages of less dense peripheral region locations.

Yet, the link between regional redistribution and the urbanization dynamic would appear to be more tenuous for the new post-1980 shifts. Can we necessarily conclude that the recent growth in Vining et al.-defined core regions is associated with the return to more traditional urbanization patterns? Or can the recent core region growth coexist with the less concentrated settlement patterns that emerged during the 1970s?

The latter scenario is certainly a logical possibility since core regions, as defined by Vining et al., constitute broad political divisions that generally include large stretches of inhabitable, low density, nonmetropolitan territory. Although regions represent political divisions that have been historically and politically dominant in their nations' development histories, their boundaries are by no means coincident with those of the major metropolitan centers. For example, in the United States, Vining and his collaborators define the core region to be comprised of the combined Northeast and Midwest census regions. Although 54 percent of these regions' 1980 population 
resided in metropolitan areas with populations greater than one million and an additional 16 percent in metropolitan areas greater than one-quarter million in size, 22 percent resided in nonmetropolitan territory and an additional 8 percent in metropolitan areas with population less than 250,000 .

To shed light on the continued association between regional and metropolitan area population change, three explanations for the 1970s counterurbanization phenomenon are presented here that differ in their expectations for the future. The discussion indicates what each implies for future "core region" growth and the extent to which it suggests a linkage between regional redistribution and the urbanization process.

\section{EXPLANATIONS OF COUNTERURBANIZATION}

The three explanations can be termed: period explanations, regional restructuring explanations, and deconcentration explanations. A more detailed discussion of the regional restructuring and deconcentration explanations appears in Frey (1987).

Period explanations attribute the metropolitan area declines and nonmetropolitan gains to an array of unique economic and demographic circumstances that converged during the 1970s. The middecade recession reduced the job-generating capacities of large cities and metropolitan areas. A series of economic dislocations induced by mounting foreign competition led to "deindustrialization-related" disinvestment in manufacturing activities and significant employment in those (largely core region) metropolitan areas where heavy manufacturing constituted a key economic sector. Other period events enhanced nonmetropolitan growth in the "peripheral" South and West regions. The energy crisis led to the development of extractive industries in western nonmetropolitan areas, the ascension of baby boom cohorts into college ages facilitated the growth of nonmetropolitan state and community colleges, and the booming rural-based recreation industry was abetted by a growing "footloose" elderly population during this period. In short, these period explanations imply that the 1970 s counterurbanization represented a temporary distortion of long-term urbanization patterns.

Regional restructuring explanations attribute 1970s metropolitan area decline to some of the same economic dislocations as the period explanations. Yet, restructuring theorists view "deindustrializationrelated" decline as a short-term episode leading towards the new spatial organization of production. This new spatial organization is associated with expanding world-wide markets, improved communications and production technologies, and, most important, the rise of the multilocational corporation. According to this scenario, continued agglomeration will occur in those metropolitan areas that function as advanced service centers and as headquarter nodes for 
multinational corporations, banks, and like institutions. Growth is also foreseen in areas with knowledge-based industries associated with high-tech research and development. On the other hand, metropolitan areas that cannot successfully make the production-to-services transformation will continue to decline. Reduced growth prospects are also anticipated for smaller metropolitan and nonmetropolitan areas that engage in routine production and consumer service activities. Hence, the regional restructuring explanation views the 1970 s counterurbanization as a necessary but intermediate stop on the way towards a new metropolitan functional hierarchy.

Deconcentration explanations view the 1970s counterurbanization tendencies as a more fundamental break with the past. Citing as evidence the unprecedented metropolitan declines and the pervasive "down the size hierarchy" migration flows, its proponents are quick to dismiss these tendencies as the results of mere period shocks or a temporary restructuring in the organization of production. Rather, they place considerable importance on the increased residential space flexibility that is accorded to the resident-consumer (Wardwell 1980) and take the view that longstanding preferences towards lower density locations are becoming less constrained by institutional and technological barriers. Changes in the industrial structure, a rising standard of living, and technical improvements in communication and production are leading away from a situation where both producer and consumer space are dictated by production constraints. As a consequence, the post-1970 counterurbanization is seen as the beginning of a long-term shift away from urban agglomerations in both core and peripheral regions.

\section{ALTERNATIVE FUTURE SCENARIOS}

All of the above explanations attempt to account for the 1970s counterurbanization phenomenon. Yet, each implies a different post1980 scenario for urban and regional population redistribution. Both the period and regional restructuring explanations anticipate a reemergence of urbanization tendencies and suggest (at least implicitly) the link to further core region gains. Period analysts' expectations are most straightforward because they foresee a return to past urban tendencies - as energy costs go down, as the demographic structure becomes more stable, and as labor markets adjust to economic shocks. Led by the largest metropolitan areas, the core regions will take on pre-1970 growth levels as "periphery-to-core" regions, "up the size hierarchy" migration streams re-emerge.

The regional restructuring scenario differs slightly from this one. The re-emergence of urban agglomeration that is likely to be centered, to a large degree, within the nation's core region also is envisioned because the largest advanced service centers that are expected to dominate the urban hierarchy already exist or are likely to emerge 
inside the Northeast or Midwest census regions. New York City, the home of a plurality of corporate headquarters, should receive strong growth impulses. Chicago, Philadelphia, and Boston should also fare well. Large advanced service centers located in the peripheral South and West regions will also gain under this scenario (Los Angeles, San Francisco, Dallas, Atlanta, and Miami). Still, the strong historical and institutional advantages held by many large core region areas suggest that this region will continue to gain if the regional restructuring's expectations came to pass.

The continued linkage between regional and urban redistribution processes is most tenuous with the deconcentration explanation. Although this explanation does not deny the possibility that some future agglomeration will take place in selected areas, its overriding long-term scenario is one of a pervasive deconcentration of the population to low density, high amenity small metropolitan areas, and nonmetropolitan territory. Because the potential area for such development is so much more abundant in the nation's South and West regions than in the North, the deconcentration explanation's longterm scenario would appear to favor growth in the former "peripheral" regions. It is possible that core region growth will be consistent with the premises of the deconcentration explanation since the Northeast and, particularly, the Midwest census regions possess a vast expanse of underdeveloped territory. However, in this case, unlike with the earlier explanations, core region growth would not be synonymous with the resurgence of urban agglomeration.

\section{A PRELIMINARY ASSESSMENT}

It is beyond the scope of this article to evaluate with precision how closely the post-1980 core region growth coincides with any of the explanations just presented or how strongly this growth can be linked with the urbanization dynamic. However, the annualized growth rates presented in Table 1 provide some suggestive clues. When one compares the rates across North metropolitan size classes in an average early 1980s year with those for an average 1970s year, one might be tempted to associate the new core region growth with the re-emergence of urbanization. In this comparison, largest metropolitan areas represent the only North category that gains. Moreover, when one makes the same comparison for large individual North metropolitan areas (lower panel of Table 1), one might be tempted to adopt the regional restructuring's explanation for post-1980 growth. In this comparison greatest gains are shown for metropolitan areas that hold advanced service functions - New York, Philadelphia, Boston, Minneapolis-St. Paul, and Kansas City; declines are shown for metropolitan areas with strong manufacturing components Detroit, Pittsburgh, and Buffalo. Such 1970s-to-1980s comparisons have been made by commentators who suggest that counterurban- 
TABLE 1

COMPARISON OF ANNUALIZED GROWTH RATES, 1960-1985

\begin{tabular}{lccccc}
\hline \hline & \multicolumn{2}{c}{ Annualized Growth Rate } & & $1980-85$ & $1980-85$ \\
\cline { 2 - 6 } & & & & $\begin{array}{c}\text { minus } \\
\text { minus }\end{array}$ & $\begin{array}{c}\text { mino-70 } \\
\text { Area }\end{array}$ \\
\hline
\end{tabular}

Region and Metropolitan Size Categories ${ }^{\mathrm{a}}$

North

$1,000,000+$

$1.1-0.2$

0.4

$-0.9$

250,000-999,999

1.1

0.5

$-0.2$

$-0.8$

Under 250,000

1.1

0.7

$-0.5$

$-0.9$

Nonmetropolitan

0.3

0.8

0.2

$-0.6$

$-0.1$

South

$1,000,000+$

250,000-999,999

$2.8 \quad 2.1$

$2.1 \quad 2.3$

0.2

$-0.5$

Under 250,000

$\begin{array}{lll}1.6 & 1.9 & 1.8\end{array}$

$-0.1$

0.2

Nonmetropolitan

$\begin{array}{lll}1.3 & 1.9 & 1.6\end{array}$

$-0.3$

0.3

West

$1,000,000+$

250,000-999,999

0.2

1.6

1.0

$-0.6$

0.8

Under 250,000

$\begin{array}{ll}2.6 & 1.8\end{array}$

2.1

0.3

$-0.5$

$2.4 \quad 2.6$

$-0.3$

$-0.1$

Nonmetropolitan

$2.0 \quad 3.3$

2.3

$-1.2$

0.1

$\begin{array}{lll}0.9 & 2.7 & 1.8\end{array}$

$-0.9$

0.9

Selected North Metropolitan Areas

\begin{tabular}{lrrrrr} 
New York & 1.1 & -0.6 & 0.4 & 1.0 & -0.7 \\
Philadelphia & 1.1 & -0.1 & 0.3 & 0.4 & -0.8 \\
Boston & 1.0 & -0.1 & 0.3 & 0.4 & -0.7 \\
Minneapolis-St. Paul & 2.1 & 0.7 & 1.1 & 0.4 & -1.0 \\
Kansas City & 1.4 & 0.4 & 0.8 & 0.4 & -0.6 \\
Columbus & 1.9 & 0.7 & 0.7 & 0.0 & -1.2 \\
Detroit & 1.3 & -0.1 & -0.7 & -0.6 & -2.0 \\
Pittsburgh & 0.0 & -0.6 & -0.7 & -0.1 & -0.7 \\
Buffalo & 0.3 & -0.8 & -0.9 & -0.1 & -1.2 \\
\hline
\end{tabular}

\footnotetext{
${ }^{a}$ Metropolitan area size categories and boundaries are consistent with 1980 census definitions for SCSAs and SMSAs. Within New England, county approximations are employed.
}

Sources: U.S. Census of Population: 1960, 1970, 1980, and 1985 postcensal population estimates compiled by the U.S. Census Bureau. 
ization tendencies are subsiding and that a return to more traditional urbanization will occur.

However, given the strong redistribution reversals that occurred during the 1970s, it is more appropriate to compare the early $1980 \mathrm{~s}$ growth rates with the rates for the $1960 \mathrm{~s}$ - a decade when traditional urbanization patterns were still evident. When this comparison is made (last column of Table 1), a very different picture emerges. In comparison to an average 1960s year, average 1980s growth rates for each North metropolitan size category fare much worse. This result holds true for each large individual North metropolitan area shown in Table 1, as well as the nine other large North metropolitan areas that are not shown. When the same 1960s-to-early-1980s comparison is made across all 12 regional and metropolitan area categories, the only 1980s gains are shown for smaller metropolitan areas and nonmetropolitan areas in the "peripheral" South and West. Results of these comparisons, more appropriate ones for assessing long-term redistribution shifts, provide greater support for the deconcentration explanation than for the other two explanations of post-1980 growth tendencies.

What, then, can be concluded about linkage between regional and urban redistribution processes in the 1980s? An examination of $1980-85$ growth rates (column 3) suggests the answer. There is virtually no difference in the growth rates displayed across each of the four metropolitan size categories within the North region. Moreover, these northern growth rates lie decidedly below comparable rates displayed in the South and West regions. Together, these patterns suggest that regional growth distinctions are becoming more important than metropolitan size distinctions. Although early 1980s growth patterns serve to moderate, slightly, the strong counterurbanization tendencies of the 1970s, settlement patterns within the nation's broad regions are far more diffuse than those that existed during the traditional urbanization years. These data suggest a disassociation between regional and urbanization redistribution patterns. While 1970 s core region declines may have been strongly linked to the counterurbanization process, post-1980 core region gains do not appear to signal a return to the metropolis.

\section{REFERENCES}

Frey, W. H. 1987. Migration and depopulation of the metropolis: Regional restructuring or rural restructuring? American Sociological Review, 52: 240-57.

Frey, W. H. and Speare, A., Jr. 1988. Regional and metropolitan growth and decline in the United States. A 1980 Census Monograph. New York: Russell Sage.

Vining, D. R., Jr. and Kontuly, T. P. 1978. Population dispersal from major metropolitan regions: An international comparison. International Regional Science Review 2, 1: 49-73.

Vining, D. R., Jr. and Pallone, R. 1982. Migration between core and peripheral 
regions: A description and tentative explanation for the patterns in 22 countries. Geoforum 13, 4: 339-410.

Wardwell, J. M. 1980. Toward a theory of urban-rural migration in the developed world. In New directions in urban-rural migration, eds. D. L. Brown and J. M. Wardwell. New York: Academic Press. 